\title{
Informes
}

\section{Carmen A. Miró: Premio Daniel Cosío Villegas}

Marco A. Gandásegui, hijo*

Carmen Miró manda sus saludos y siente mucho no poder acompañarnos debido a sus quebrantos de salud. Se siente profundamente emocionada por este galardón que le otorga El Colegio de México, institución que siempre ha admirado, quiere y en la cual trabajó muchos años.

Ella ha sido una mujer que desde temprana edad se enfrentó a toda clase de adversidades. Por un lado, era de cuna humilde. Por el otro, era mujer en un mundo de hombres. Supo superar ambos estigmas, y gracias a muchas circunstancias se elevó para cumplir con lo que consideraba siempre sus compromisos.

A fines de la década de 1930, graduándose con honores del Instituto Nacional, fue reclutada para servir de secretaria del entonces presidente de la República, en una época en que todavía ése era un oficio de hombres. Se fue a estudiar a Estados Unidos a temprana edad, e hizo sus primeras aproximaciones a la sociología funcionalista que ya había destronado al anquilosado positivismo. Poco después acudió a la Escuela de Economía de Londres, donde fue abrumada por las diversas corrientes de pensamiento de la segunda posguerra. Regresó con un pensamiento crítico consolidado que crecería con los años.

A pesar de estas experiencias académicas, Carmen no se sentía completa y seguía buscando respuestas a sus múltiples interrogantes. Desde sus

* Profesor de Sociología en la Universidad de Panamá e investigador asociado del CELA. Correo electrónico: gandasegui@hotmail.com

Nota del editor: Palabras pronunciadas en la ceremonia de entrega del Premio Daniel Cosío Villegas 2016 a la doctora Carmen A. Miró, otorgado por El Colegio de México y la Fundación Colmex en reconocimiento a su extraordinaria trayectoria en las ciencias sociales, la demografía latinoamericana, el pensamiento sobre la población y el desarrollo, y por su papel como animadora y forjadora de instituciones. El Colegio de México, A.C., jueves 16 de febrero de 2017. 
tiempos de estudiante en el Instituto Nacional, era políticamente inquieta y militaba en los grupos políticos estudiantiles. En la Universidad de Panamá destacó en la fundación de la Federación de Estudiantes de Panamá (FEP), que tenía fuertes ribetes nacionalistas y de transformaciones sociales. Después militó en el Frente Patriótico de la Juventud, movimiento que abrió horizontes para una juventud prisionera de una oligarquía conservadora y también para los trabajadores que vivían en zozobra permanente como consecuencia de la represión de patrones y gobernantes.

En las décadas de 1940 y 1950 destacó en la Universidad de Panamá, dirigiendo la cátedra de Estadística. También fue directora de Estadística y Censo del gobierno, encabezando el primer censo científico que se realizó en Panamá en 1950. Tanto en la Universidad de Panamá como en el gobierno tuvo oportunidad de enfrentar a los sectores más conservadores. Introdujo cambios en el método de enseñanza y, a la vez, elevó los estándares éticos en el sector público.

En 1959 se trasladó a Santiago de Chile para encabezar el recién creado Centro Latinoamericano de Demografía (Celade), tan querido por todos los presentes. Carmen no se sentiría realizada en Celade si no era proyectando su carácter y su energía en el espíritu de los estudiantes que venían de todos los países de la región. Confesaba que no se podía comparar con los más brillantes demógrafos, sociólogos y estadígrafos del mundo que poco a poco fueron formando parte de su equipo. Sus reuniones con los especialistas de la CEPAL también fueron para ella una escuela permanente.

Carmen, sin embargo, tenía algo que no poseían sus compañeros en el mundo académico que la rodeaban: su carácter, su dedicación y, sobre todo, su liderazgo. Sus obras no son textos o manuales: son guías para el trabajo y para la lucha. Entendió desde su llegada a Santiago que su misión era construir un mundo mejor. El sistema capitalista siempre le ha dado una importancia estratégica a los problemas de la población. Adam Smith y Robert Malthus, así como la crítica de Carlos Marx, siguen siendo hasta el presente los baluartes teóricos de la demografía. A mediados del siglo XX las nociones catastróficas de la población se habían apoderado de los círculos funcionalistas más próximos a quienes diseñaban políticas. Cuando Carmen se enfrentó, en la CEPAL, a los políticos que decían que el tamaño de la población y su crecimiento en la periferia del sistema capitalista constituían un peligro para la estabilidad mundial, respondió con argumentos razonados que no existía tal "explosión" demográfica.

El problema no era la población, era la estructura social y las contradicciones que generaba. Mucho antes que los cambios generados por políticas públicas (buenas o malas), orientadas hacia un desarrollo capitalista depen- 
diente, hicieran disminuir las tasas de crecimiento de la población en la región, Carmen lo había teorizado.

Especial mención merece el trabajo de Carmen en el campo del estudio del envejecimiento poblacional. Nuevamente, desmitificó la creencia que la población de edad más vieja desestabilizaría las sociedades de la región. Las preguntas absurdas sobre quién cuidaría a los viejitos, sin hacer referencia al sistema social en que están insertos, fueron rechazadas por Carmen. Demostró cómo estas nociones formaban parte de los intereses de los sectores sociales que querían destruir instituciones -como la seguridad social- para orientarlas por otras vías contrarias a las necesidades de quienes se veían obligados a retirarse del mundo laboral.

Carmen desmitificó las nociones que asociaban el envejecimiento de la población con la quiebra inevitable del régimen de gasto público social. Aclaró que la medida estadística de la esperanza de vida no era un indicador para determinar la capacidad productiva de la población de mayor edad. También demostró que el envejecimiento de la población no significaba que aumentaría el consumo de los no productivos mayores de 60 años de edad. Igualmente, combatió la propuesta de los políticos corruptos que asocian el envejecimiento de la población con la quiebra de los sistemas de seguridad social. Ésta no depende tanto de la edad de la población, depende de las estrategias políticas de los gobernantes.

A nombre de Carmen, nuevamente, muchas gracias. 
